\title{
USING VIRTUAL MODELLING FOR AS/RS MATERIAL FlOW MANAGEMENT
}

\author{
Constantin Adrian Popescu, Cicerone Laurentiu Popa, \\ Costel Emil Cotet \& George Enciu
}
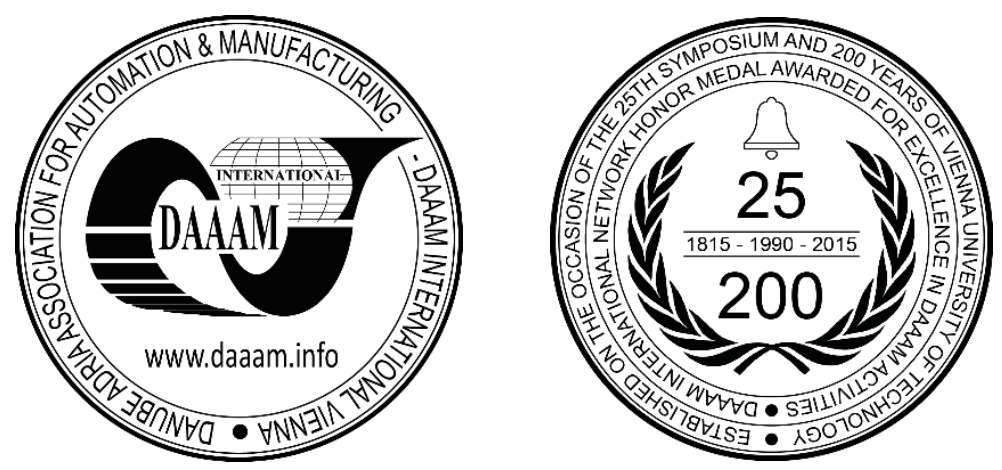

This Publication has to be referred as: Popescu, C[onstantin] -[ Adrian]; Popa, C[icerone] L[aurentiu]; Cotet, C[ostel] E[mil] \& Enciu, G[eorge] (2016). Using Virtual Modelling for AS/RS Material Flow Management, Proceedings of the 27th DAAAM International Symposium, pp.0180-0186, B. Katalinic (Ed.), Published by DAAAM International, ISBN 978-3-902734-08-2, ISSN 1726-9679, Vienna, Austria

DOI: $10.2507 / 27$ th.daaam.proceedings.027

\begin{abstract}
In today's industries, the storage of workpieces, components and final products has become an issue due to lack of storage spaces and to high storage costs. Companies are trying to find new solutions for material flow optimization in warehouses in order to obtain the best storage position of products. The main goal of the paper is to present how mathematical and virtual modelling can be applied in this particular area of industrial logistics. The first part of the paper describes a mathematical model based on the Markov chain theory used for industrial logistics applications. The second part of the paper contains case studies which demonstrate how Markov chain theory can be used for virtual material flow modelling of AS/RS (Automated storage/Retrieval system) systems in order to obtain the best storage position of products considering: available position, estimated storage time, product type, weight etc.
\end{abstract}

Keywords: Markov chain; virtual modelling; AS/RS system; material flow management.

\section{Introduction}

In this paper we present some of the research results obtained in the industrial logistics laboratory from our faculty where multiple logistic systems and platforms have been made from scratch in the last four years for educational and research purposes. For each developed system and platform a virtual model was made using dedicated software applications (CATIA, SolidWorks, Inventor) and for each system and platform a material flow simulation was made to achieve a preliminary diagnosis and to validate the identified optimization solution for the chosen architecture configuration. The material flow modelling, simulation and optimization for the storage systems represent some of the major concerns, considering the demands coming from our industry partners. Due to lack of storage spaces and to high storage costs, the storage of workpieces, components and final products has become an issue. Companies are trying to find new solutions for material flow optimization in warehouses in order to obtain the best storage position of products considering: available position, product type, estimated storage time etc.

In one of our previous papers we presented how CAD (Computer Aided Design) and the simulation results of a virtual model were used to develop and to optimize the performances for an educational platform considering various manufacturing scenarios [1]. In the present paper we extend our research by looking for the best storage solution using 
the Markov chain model. In the second part of the paper we will present a case study which demonstrate how Markov chain theory can be used for virtual material flow modelling of AS/RS (Automated storage/Retrieval system) systems in order to obtain the best storage position of products considering: available position, estimated storage time, product type, weight etc.

\section{Literature Review}

The function of a material storage system is to store materials for a period of time and to permit access to those materials when required [2]. An automated storage/retrieval system (AS/RS) represents a combination of equipment and controls, which handles, stores and retrieves materials with precision, accuracy and speed under a defined degree of automation [3]. Automated Storage and Retrieval Systems (AS/RSs) are widely used in the industry in order to store and retrieve unit-loads without interference of an operator. An AS/RS is used for raw material, work-in-process and finished goods. We can find AS/RS systems in many domains such as: warehousing and distribution, manufacturing, automotive, pharmaceutical etc. The main advantages of AS/RSs are savings in labour costs and floor space, increased reliability, and reduced error rates [4].

Elements from Markov chain theory are used in many domains, among which: physics, medicine, chemistry, economics, sociology, IT\&C, data storage etc. Markov chain models are widely used in engineering and manufacturing in detecting machine failures in a production system [5]. Literature review shows many approaches regarding the use of Markov chain in the manufacturing and industrial logistics domains. For example, a Markovian model is used to determine optimal equipment adjustment in multi-stage production systems taking variable cost into consideration. The goal is to maximize the expected profit per item of a multi-stage production system by determining best adjustment points of the equipment used based on technical product specifications defined by designer [6]. A similar study regarding the analysis of a Markov chain model of a multistage manufacturing system with inspection, rejection and rework was conducted by $\mathrm{Yu}$ and Briker (1990) [7]. Atali and Ozer (2012) show how to better manage multi-item production systems with production smoothing constraints at each stage when the demand environment fluctuates. Also, in their paper a model is presented which provides a cost upper bound for production systems that allow a manager to keep inventory of intermediate products. [8].

Markov chain models have been used by many authors to capture the influence on demand by factors such as weather, product age, economic conditions, and price competition. In manufacturing, random production yields are influenced by factors such as breakdowns, repairs, maintenance. [9]. Pillai and Chandrasekharan present a Markov model which describes a material flow in a production system under uncertainties due to scrapping and reworking. Their analysis shows clearly the interaction between design and control decisions, and it provides an opportunity for the management to analyse quality-related problems. [10]

Virtual modelling represents an important step during the development of a logistic system. However, in the studied papers the virtual modelling of the storage system or manufacturing system was not made. In our paper, in addition to the Markov chain model we will present the virtual model of the storage system (AS/RS storage system). Virtual modelling reduces the design time, can be used to test structures and constructions for strengths before they are physically built, can be very easily and quickly modified at any time. Also, by using virtual modelling, mistakes in design or production can be avoided, the structural elements can be used in the material flow simulation etc.

\section{Mathematical and Virtual Modelling}

Due to the probabilistic stages through which the physical systems generally go through, it can be admitted that their evolution is described by a random process, defined by a family of random variables. Knowing the stages prior to the moment $n$ has a contribution in knowing the stage at the moment $n$. Similarly, the functioning of a logistic subsystem is characterized through a succession of stages in which the subsystem can be at a certain moment, and depending on this, decisions can be taken regarding its evolution.

The algorithm for determining the possible configurations for the passing from the initial stage to the present stage for a storage structure specific for AS/RS systems with $\mathrm{n}$ storage positions is the following:

- the matrix of the current stage corresponding to the AS/RS storage system is selected;

- all the combinations that have as basis the matrix for the current stage and that can be obtained through the adding of a single element in the matrix structure on one of the free positions (marked with 0 ) are identified.

- the two stages are repeated for all elements equal with 0 , until the matrix of the current stage has all the elements equal with 1 ;

- for each passing the relation between the initial stage and the current stage is identified, so that no identical stages will exist corresponding for the same number $\mathrm{k}$;

- at the end, for every passing from an initial stage and the current stage, $p$ possibilities for passing where $p=\mathrm{n}-k$, and $\mathrm{n}$ represents the number of storage positions and $\mathrm{k}$ represents the parts stored at a given moment. 


\subsection{The Mathematical Model}

The matrix associated to AS/RS system will have the following structure:

$$
A=\left[\begin{array}{cccccc}
a_{n 1} & a_{n 2} & \ldots & a_{n j} & \ldots & a_{n m} \\
\vdots & \vdots & & \vdots & & \vdots \\
a_{i 1} & a_{i 2} & \ldots & a_{i j} & \ldots & a_{i m} \\
\vdots & \vdots & & \vdots & & \vdots \\
a_{21} & a_{22} & \ldots & a_{2 j} & \ldots & a_{2 m} \\
a_{11} & a_{12} & \ldots & a_{1 j} & \ldots & a_{1 m}
\end{array}\right]
$$

where $1 \leq i \leq m$ și $1 \leq j \leq n$

$$
\text { and } a_{i j}=\left\{\begin{array}{l}
0, \text { for free position } \\
1, \text { for occupied position }
\end{array}\right.
$$

The general shape of the passing matrix results:

$$
P=\left[\begin{array}{ccccc}
\frac{n_{11}}{x_{1}} & \frac{n_{12}}{x_{1}} & \frac{n_{13}}{x_{1}} & \cdots & \frac{n_{1 c}}{x_{1}} \\
\frac{n_{21}}{x_{2}} & \frac{n_{22}}{x_{2}} & \frac{n_{23}}{x_{2}} & \cdots & \frac{n_{2 c}}{x_{2}} \\
\vdots & & & \\
\frac{n_{c 1}}{x_{c}} & \frac{n_{c 2}}{x_{c}} & \frac{n_{c 3}}{x_{c}} & \cdots & \frac{n_{c}}{x_{c}}
\end{array}\right]
$$

Elements of the passing matrix can be:

$$
\begin{aligned}
& \left\{\begin{array}{l}
0-\text { if no transition can't be made from the } s_{i_{T}} \text { stage to the } s_{i_{T}} \text { stage } \\
0<\frac{n_{i_{T} j_{T}}}{x_{j_{T}}}<1-\text { if transition can be made from the } s_{i_{T}} \text { stage to the } s_{i_{T}} \text { stage }
\end{array}\right. \\
& i_{T} \nrightarrow j_{T} \text { if } p_{i_{T} j_{T}}=0 \\
& i_{T} \rightarrow j_{T} \text { if } p_{i_{T} j_{T}} \neq 0
\end{aligned}
$$

Determining the passing matrix for the stages in which the storage structure of the AS/RS system can be found is based on the following algorithm:

- for all possible combinations, in each matrix the most favourable storage position is identified, taken into account the storage time (the time necessary for the transport of the workpiece from the in/out position to the storage place) and the occupation matrix. The storage time is determined depending on the transportation speed specific for the transfer/transport system that varies depending on the weight of the workpiece that needs to be stored;

- the vector corresponding to the stages in which the AS/RS specific storage structure can be found is written;

- based on the algorithm for establishing the possible configurations for passing from stage $S_{i_{T}}$ to the present stage $S_{j_{T}}$ the passing matrix is completed with the values calculated for each position corresponding the storage spaces;

- the $\sum n_{i_{T} j_{T}}=x_{j_{T}}$ formula is applied for each of the lines of the resulted matrix;

- The matrix is determined in the following way: each element of the passing matrix that differs from 0 will be:

$$
p_{i_{T} j_{T}}=\frac{n_{i_{T} j_{T}}}{\sum_{j_{T}=1}^{c} n_{i_{T} j_{T}}}
$$

\subsection{The Virtual Model of the AS/RS System}

The complete functioning cycle of the transfer-transport system specific to the AS/RS system, at the loading on the storage structure is:

- Positioning the transport/transfer system in front of the entry conveyor;

- Extending the mobile segments specific to the transfer subsystem for picking up the part $-\mathrm{x}$ axis;

- The vertical movement of the transfer subsystem on a short distance $-\mathrm{z}$ axis;

- The retreat of the mobile segments specific to the transfer subsystem in the 0 position - the $\mathrm{x}$ axis; 
- The movement of the transfer/transport system on the two axes ( $y$ and $z$ ) for the positioning in front of the specific storage position where the part will be placed;

- The extension on the mobile segments specific to the transfer subsystem for placing the stored part on the $\mathrm{x}$ axis;

- The vertical movement of the transfer subsystem on a short distance - the $\mathrm{z}$ axis, in order to place the part in the specific storage position;

- The withdrawal of the mobile segments specific to the transfer subsystem in the 0 position, on the $\mathrm{x}$ axis.

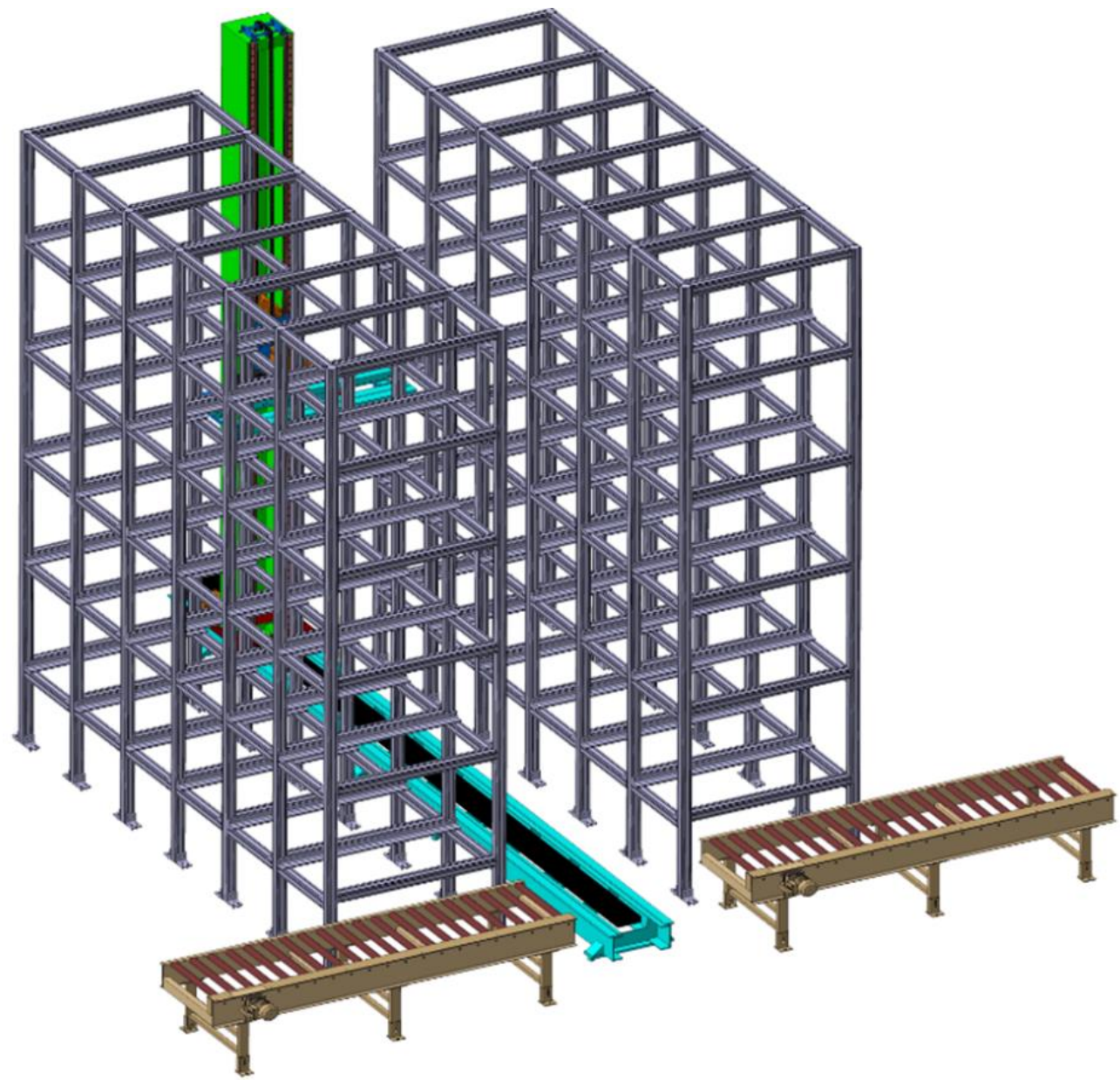

Fig. 1. The virtual model of the AS/RS system
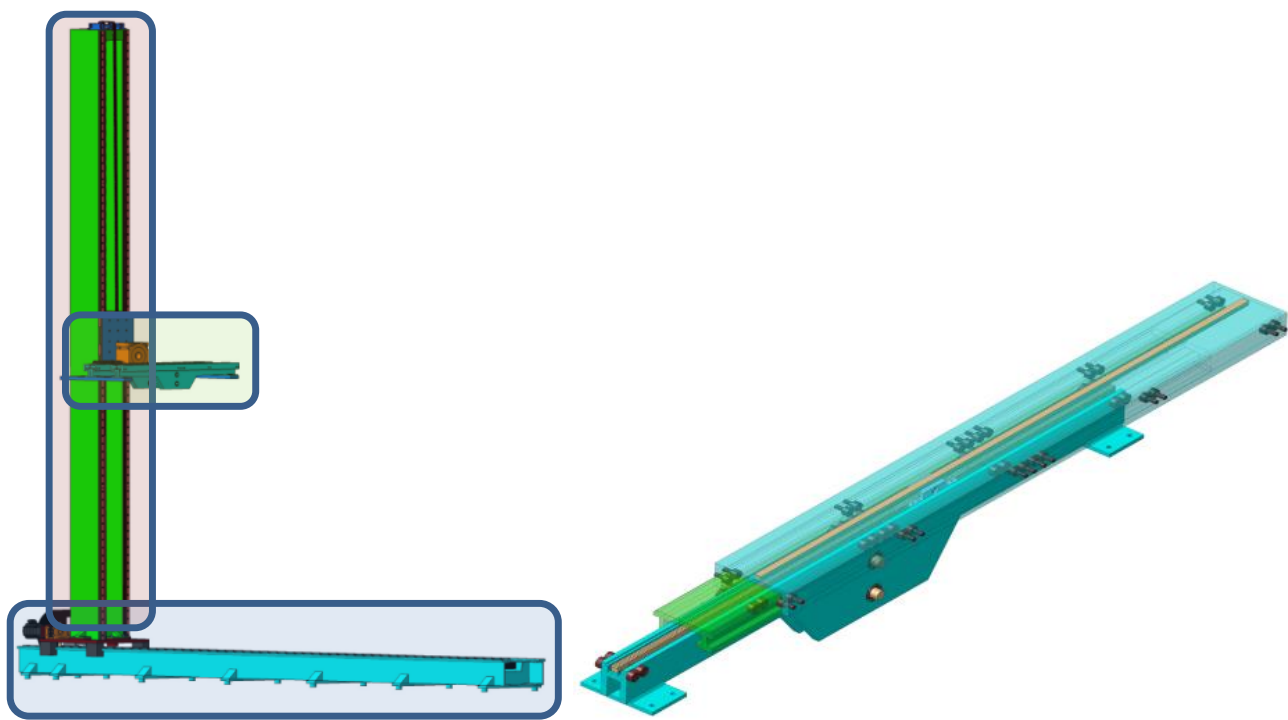

Fig. 2. Main transport/transfer components of AS/RS system 


\section{Case Study}

The main objective is to reduce the total functioning time of the specific transport-transfer AS-RS system for the presented assembly. The maximum travelled distance for the same type and number of parts will be underlined. For the simplification of the analysis, 9 storage places were considered corresponding to a single rack.

Entry data:

- Nr.ord - The order in which the parts will be removed from the rack;

- L - The length of a storage position;

- $\mathrm{H}$ - The height of a storage position;

The general entry data specific for the application: L: $0.77 \mathrm{~m} ; \mathrm{H}: 1.10 \mathrm{~m}$

For running the application two classes are used:

- The Element.cs class is used to store the initial vector and it has the following proprieties: stringRepresentation (ex: 000100111), OneCount (ex. "1" from StringReprezentation), DifferencePosition, DifferenceRowPosition, DifferenceColumnPosition, DijValue (Dij value for current matrix), TijValue (Tij value for current matrix).

- The Representation class permits the running of all steps necessary for obtaining the final result and it has the following proprieties: MinValue, MinValuePosition, FinalVector, LowerElement.

The program based on the mathematical model, personalized for 9 storage positions, is formed from a single "MainWindow" view that contains a button for launching the program and textboxes for showing the results.

public bool Compare(string value, int lines, int columns)

i

int diferences $=0$;

if (this.StringReprezentation.Length != value.Length)

i

$$
\}
$$

return false;

for (int $i=0 ; i<$ this.StringReprezentation.Length $; i++$ )

f

if (this.StringReprezentation $[i] !=$ value[i])

i

diferences ++ ;

this.DifferencePosition $=i$;

if (diferences > 1)

i

this.DifferencePosition = -1;

\}

return false;

\}

\}

this.DifferenceRowPosition $=($ int $)($ this.DifferencePosition $/$ columns $)$;

this.DifferenceColumnPosition $=($ int $)($ this.DifferencePosition \% columns $)$;

return true;

\}

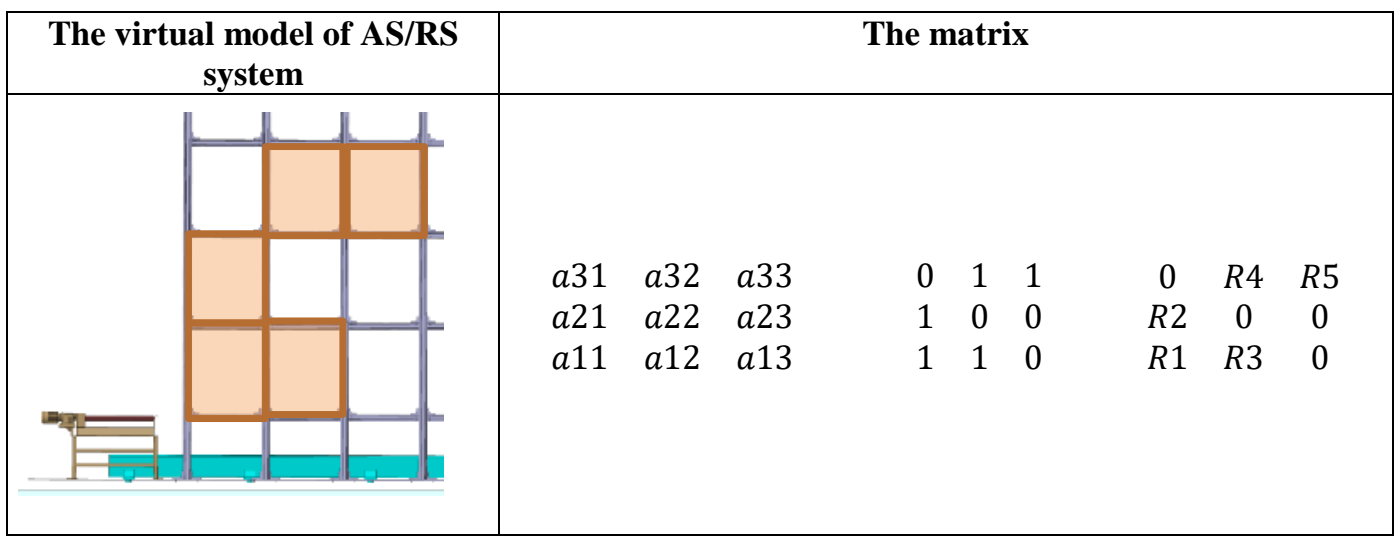

Table 1. The configuration from which we start in our case study 
After obtaining the passing matrix, it is multiplied with the vectors of the current stage, obtaining a vector for which the minimal value will be determined. After running the program, the data is shown on the screen with the method "Show results()". For a complete run on the program (meaning from the start of the initial matrix $=0$ ) the program assures a running of maximum $3 \times 3$. Because the program generates all possible stages, the passing stage will contain 29 lines and 29 columns, a longer execution time being necessary in this case. The configuration from which we start is presented in table 1.

Case 1. The loading of the storage structure with parts depending on the minimal distance which the transfer - transport system travels. Storage time is considered as being constant.

\begin{tabular}{|c|c|c|c|c|c|}
\hline Nr. crt. & Action & $\begin{array}{c}\text { Storage } \\
\text { position }\end{array}$ & $\begin{array}{c}\text { Part } \\
\text { Type }\end{array}$ & $\begin{array}{c}\text { Nr. } \\
\text { ord. }\end{array}$ & Distance [m] \\
\hline 1 & Loading & $\mathrm{a}[1][3]$ & $\mathrm{T} 5$ & - & 2.31 \\
\hline 2 & Loading & $\mathrm{a}[2][2]$ & $\mathrm{T} 4$ & - & 1.89 \\
\hline 3 & Unloading & $\mathrm{a}[1][1]$ & $\mathrm{T} 1$ & - & 0.77 \\
\hline 4 & Loading & $\mathrm{a}[1][1]$ & $\mathrm{T} 5$ & - & 0.77 \\
\hline 5 & Unloading & $\mathrm{a}[1][2]$ & $\mathrm{T} 2$ & - & 1.54 \\
\hline 6 & Loading & $\mathrm{a}[1][2]$ & $\mathrm{T} 4$ & - & 1.54 \\
\hline 7 & Unloading & $\mathrm{a}[2][1]$ & $\mathrm{T} 3$ & - & 1.34 \\
\hline 8 & Unloading & $\mathrm{a}[3][2]$ & $\mathrm{T} 4$ & - & 2.68 \\
\hline 9 & Unloading & $\mathrm{a}[3][3]$ & $\mathrm{T} 5$ & - & 3.19 \\
\hline 10 & Loading & $\mathrm{a}[2][1]$ & $\mathrm{T} 1$ & - & 1.34 \\
\hline 11 & Loading & $\mathrm{a}[3][1]$ & $\mathrm{T} 2$ & - & 2.33 \\
\hline 12 & Unloading & $\mathrm{a}[1][3]$ & $\mathrm{T} 1$ & - & 2.31 \\
\hline 13 & Unloading & $\mathrm{a}[3][1]$ & $\mathrm{T} 2$ & - & 2.33 \\
\hline 14 & Loading & $\mathrm{a}[1][3]$ & $\mathrm{T} 2$ & - & 2.31 \\
\hline 15 & Unloading & $\mathrm{a}[2][2]$ & $\mathrm{T} 4$ & - & 1.89 \\
\hline 16 & Loading & $\mathrm{a}[2][2]$ & $\mathrm{T} 1$ & - & 1.89 \\
\hline 17 & Unloading & $\mathrm{a}[1][3]$ & $\mathrm{T} 5$ & - & 2.31 \\
\hline 18 & Loading & $\mathrm{a}[1][3]$ & $\mathrm{T} 2$ & - & 2.31 \\
\hline \multicolumn{7}{|l|}{ The total distance travelled } & & 35.05 \\
\hline
\end{tabular}

Table 2. Results for case 1

Case 2. The loading of the storage structure with parts, depending on the minimal distance which the transfer transport system travels and the time the parts will remain stored (the order number $-\mathrm{Nr}$. ord.).

\begin{tabular}{|c|c|c|c|c|c|}
\hline Nr. crt. & Action & $\begin{array}{l}\text { Storage } \\
\text { position }\end{array}$ & $\begin{array}{l}\text { Part } \\
\text { Type }\end{array}$ & $\begin{array}{l}\text { Nr. } \\
\text { ord. }\end{array}$ & Distance [m] \\
\hline 1 & Loading & $\mathrm{a}[2][3]$ & T5 & $55_{1}$ & 2.55 \\
\hline 2 & Loading & $\mathrm{a}[3][1]$ & $\mathrm{T} 4$ & $4_{1}$ & 2.33 \\
\hline 3 & Unloading & $\mathrm{a}[1][1]$ & $\mathrm{T} 1$ & 1 & 0.77 \\
\hline 4 & Loading & $\mathrm{a}[1][1]$ & T5 & $5_{2}$ & 0.77 \\
\hline 5 & Unloading & $\mathrm{a}[1][2]$ & $\mathrm{T} 2$ & 2 & 1.54 \\
\hline 6 & Loading & $\mathrm{a}[2][2]$ & $\mathrm{T} 4$ & $4_{2}$ & 1.89 \\
\hline 7 & Unloading & $\mathrm{a}[2][1]$ & T3 & 3 & 1.34 \\
\hline 8 & Unloading & $\mathrm{a}[3][2]$ & $\mathrm{T} 4$ & 4 & 2.68 \\
\hline 9 & Unloading & $\mathrm{a}[3][3]$ & T5 & 5 & 3.19 \\
\hline 10 & Loading & $\mathrm{a}[1][2]$ & T1 & 1 & 1.54 \\
\hline 11 & Loading & $\mathrm{a}[2][1]$ & $\mathrm{T} 2$ & 2 & 1.34 \\
\hline 12 & Unloading & $\mathrm{a}[1][2]$ & $\mathrm{T} 1$ & 1 & 1.54 \\
\hline 13 & Unloading & $\mathrm{a}[2][1]$ & $\mathrm{T} 2$ & 2 & 1.34 \\
\hline 14 & Loading & $\mathrm{a}[1][2]$ & $\mathrm{T} 2$ & 21 & 1.54 \\
\hline 15 & Unloading & $\mathrm{a}[3][1]$ & $\mathrm{T} 4$ & $4_{1}$ & 2.33 \\
\hline 16 & Loading & $\mathrm{a}[2][1]$ & $\mathrm{T} 1$ & 1 & 1.34 \\
\hline 17 & Unloading & $\mathrm{a}[2][3]$ & T5 & $55_{1}$ & 2.55 \\
\hline 18 & Loading & $\mathrm{a}[1][3]$ & $\mathrm{T} 2$ & $22_{2}$ & 2.31 \\
\hline \multicolumn{5}{|c|}{ The total distance travelled } & 32.89 \\
\hline
\end{tabular}

Table 3. Results for case 2 
The results for the two cases are presented in figure 3 (Case 1- blue, Case 2 - orange)

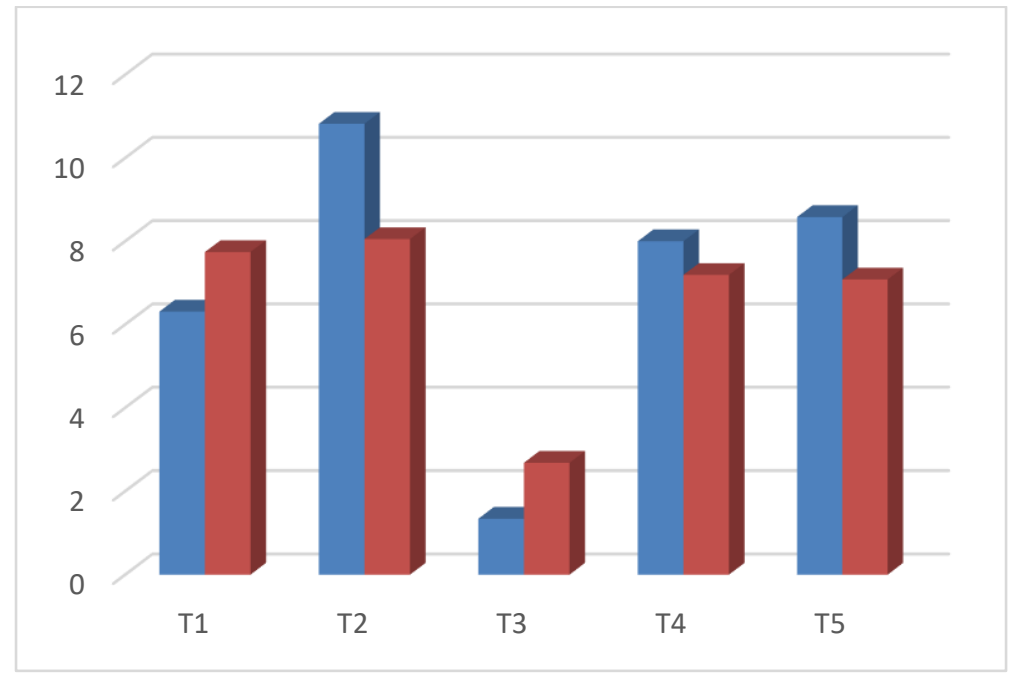

Fig. 3. The specific distance for every type of part for the two cases

\section{Conclusion}

This paper is centred on the use of mathematical and virtual modelling in optimizing the functioning of various systems in industrial logistics. The case study illustrating the proposed optimization algorithms was performed in the industrial logistics laboratory from our faculty. The application developed from the mathematical model based on the Markov chain theory allows for the reduction of the distance travelled by the transfer-transport system and of its functioning time at the moment of loading and unloading of parts. Because the passing matrix which allows the identification of the present stage of the system $-i$, from the previous stage - i-1, has a very large number of components, the case study was made for a reduced number of storage positions. Also, the passing matrix was obtained only by the quantification of the distance specific for every storage position, in relation with the in/out position and with the time period in which the part will remain stored. In the future we plan to use a different algorithm for obtaining the passing matrix and a higher number of characteristics specific to the stored part (weight of the part, the storage frequency for a certain type of part etc.).

\section{References}

[1] Cotet, C. E.; Popa, C. L.; Enciu, G.; Popescu, A.; Dobrescu T. (2016). Using CAD and Flow Simulation for Educational Platform Design and Optimization. International Journal of Simulation Modelling, Vol. 15, No. 1, 515 , ISSN 1726-4529

[2] Kumar, S. A. \& Suresh N. (2009). Production and Operations Management. New Age International Publishers, ISBN 978-8122421774, New Delhi

[3] Material Handling Industry, http://www.mhi.org

[4] Lerher, T.; Ekren, Y. B.; Sari, Z.; Rosi, B. (2015). Simulation Analysis of Shuttle Based Storage and Retrieval Systems. International Journal of Simulation Modelling, Vol. 14, No. 1, 48-59, ISSN 1726-4529

[5] Allen H. Tai; Wai-Ki Ching; Chan L. Y. (2009). Detection of Machine Failure: Hidden Markov Model Approach. Computers \& Industrial Engineering, Volume 57, Issue 2, 608-619, ISSN 0360-8352

[6] Fallah Nezhad, M. S.; Niaki, S. T. A.; Shahin, E. (2013). Markov Model to Determine Optimal Equipment Adjustment in Multi-stage Production Systems Considering Variable Cost. Iranian Journal of Operations Research, Vol. 4, No. 2, 146-160, ISSN 2008-1189

[7] Yu, K. Y. \& Bricker, D. L. Analysis of a Markov Chain Model of a Multistage Manufacturing System with Inspection, Rejection, and Rework. ISSN 0360-8352 available from: http://user.engineering.uiowa.edu/ dbricker/or_sample_quizzes/papers/MC_Mfg.pdf, Accessed: 2016-06-16

[8] Atali, A. \& Ozer, O. (2012). Stochastic Multi-item Inventory Systems with Markov-Modulated Demands and Production Quantity Requirements. Probability in the Engineering and Informational Sciences, Volume 26, Issue 2, 263-293, ISSN 0269-9648

[9] Gallego, G. \& Hu, H. (2004). Optimal Policies for Production/Inventory Systems with Finite Capacity and MarkovModulated Demand and Supply Processes. Annals of Operations Research, Vol. 126, Issue 1, 21-41, ISSN 02545330

[10] Pillai, V. M., Chandrasekharan, M. P. (2008). An Absorbing Markov Chain Model for Production Systems with Rework and Scrapping. Computers \& Industrial Engineering, Volume 55, Issue 3, 695-706, ISSN 0360-8352 